\title{
FINE STRUCTURE OF RENAL TUBULE CELLS
}

\author{
HIROSHI SAKAGUCHI and YASUNOSUKE SUZUKI \\ Department of Pathology, School of Medicine \\ Keio University
}

(Received on July 31,1958 )

Since utilization of the electron microscope in the field of histology, the fine structures of the renal tubule cells have called the attention of many investigators, who studied the morphology of the kidney, because of the peculiar organelles revealed by the electron microscope, e.g. elaborate brush border, basal intussusception and mitochondria which suggested an intimate relation between these organelles and the renal function.

As regards the fine structure of the renal tubule cells, many reports are found, but most of these are concerned with proximal convolution (Peace(7), Sjöstrand and Rhodin(13) etc.) and distal convolution (Pease(6), Takagi). Among the works of the remaining parts of the tubules, the fine structure of the thin segment of Henle by Takagi(14) and his coworkers is particularly worthy of notice.

We have been studying the correlation between the structure and function of the kidney in its physiological and pathological conditions. In previous papers, we reported the fine structures of the normal glomerulus(11) and glomerular changes in experimental nephritis (Masugi-nephritis $\left.{ }^{(12)}\right)$. In this paper, we intend to report on the electron microscopic identifications of the nephron by part in rabbit kidney.

\section{MATERIAL AND METHOD}

Normal kidneys of a rabbit were used for material. Small specimens of the renal cortical and medullal tissue were fixed in $1 \%$ buffered osmic acid immediately after the kidneys were removed from the decapitated rabbit. After three hours fixation, specimens were dehydrated in graded alcohol and embedded in methacrylates as described by Porter. Thermal expansion microtom and JUM electron microscope were used in this study.

Because of the difficulties in identifying the nephron by part with a higher magnified electron microscope, lower magnified photographs of electron microscopy were collected for use at the beginning of this study. "Later the 
fine structure of each part of the nephron was examined by highly magnified photographs.

\section{OBSERVATIONS}

Classification of the nephron has been described by Möllendorff (1930)(5), Cowdry (1950)(2), Maximow-Bloom (1950)(4) and others. From the authors' electron microscopic observation of the nephron, the most practical classification (except glomerulus) is as follows: Proximal convolution; Comparatively straight medullary portion; Loop of Henle (Descending thin limb and Ascending thick limb); Distal convolution; Collecting tubule; Papillary duct.

Hence the observation of the nephron will be described according to this classification.

\section{Proximal convolution:}

Basal portion:-At the basal portion of the proximal convoluted cell, the cell membrane forms a double infolding at a constant width of $500 \mathrm{~A}^{\circ}$ (Fig. 1). These structures have been named "basal intussusception" by Pease. Occasional dilatation of these spaces are observed due to some physiological condition. The distribution of the basal intussusception approximately coincides with the mitochondria. Usually these are observed around the mitochondria at the basal portion of the cells, but occasionally these enter into the cytoplasm near the apical portion of the cell from the basal portion.

Rhodin described that in the space of the basal intussusception lipid were filled in vivo and washed out during the fixation. Also Pease described basal intussusception as being cytoplasmic membrane because of its occasional dilatation. He also assumed that this dilatation is caused by the escape of the water soluble material into this space from the intra-cytoplasm. We also believe that the basal intussusception is a cytoplasmic membrane for the same reason as Pease's description.

Brush border:-At the apical portion of the cell, many regularly arranged thin tubes covered by cytoplasmic membrane are observed (Fig. 2). These are brush borders. In a normal rabbit, this tubular structure is $200 \mathrm{~m} \mu$ in diameter and approximately $2 \mu$ long. This brush border is closely arranged when the lumina of the nephron is blocked, although in the tubule cells when the cytoplasm is ballooned out into the lumina (so-called dome cell) the brush border is only seen at the peripheral part of the protruded cytoplasm. Concerning the significance of the so-called dome cell, some described that the existence of the dome cell and its transitional form suggested the presence of a secretary activity of the tubule cell. 
As shown in Fig. 3, in the dome cell, sometimes in addition to the mitochondria and vesicles, nucleus of the tubule cell are observed in the cytoplasmic protrusion. This fact would indicate that the dome cells are neitheir artifact nor secretory manifestations of the proximal convoluted cell. The co-existence of the cells having brush borders and the dome cell, would seem to indicate that these cells have an inter-transition, also that the latter may be formed by the former in some physiological condition. Contrary to this, Pease ${ }^{(6)}$ assumed the dome cell to be an artifact. He described that the lumina were closed, probably not so much because of collapses, but because the proximal tubule cells picked up fluid and became swollen during fixation, and under conditions of dehydration the lumina of tubules appeared wide and epithelium thin. In the present authors' experience, the lumina of the proximal convolution are usually closed and those of the straight medullary portion are always open. The authors found that a nephron described by Pease as being dehydrated convoluted tubules was the comparatively straight medullary portion and not dehydrated convoluted tubule cells as described by Pease. This will be described later.

In the cytoplasm of the cells of the proximal convolution, nuclei, vacuoles of miscellaneous size, many large rod or oval shaped mitochondria, the Golgi area and RNA granules are seen. The fine structures of these organella are generally the same as those described by other writers.

\section{Comparatively straight medullary portion:}

The diameter of this part of the nephron is approximately $15 \mu$. The height of the cells are $3.2 \mu$ to $6.0 \mu$ with a $1.0 \mu$ long brush border at the apical end of the cell. The luminal space of this part is of an irregular stellate shape and usually this space is definitely open. Contrary to this the proximal convolution is closed.

The cytoplasm of this part is much denser than that of the proximal convolution because of the high density of the intracytoplasmic small granules (RNA granule) as shown in the right half of Fig. 4.

The brush borders of this part are approximately $500 \mathrm{~A}^{\circ}$ to $700 \mathrm{~A}^{\circ}$ in diameter, $1.0 \mu$ in length and separated by a distance of from 100 to $130 \mathrm{~m} \mu$. These brush border are covered with cytoplasmic membrane similar to that of the proximal convolution (Fig. 5). At the tangential cut surface of the brush border of this portion, it is noted that there are small and separated vesicular structures. Contrary to this, the brush border of the proximal convolution has a hexagonal cut surface. 
At the basal portion of the cell the mitochondria are more abundant and larger than at the apical portion. The basal intussusception is well developed and the mitochondria-intussusception relationship approximately coincides with the proximal convolution. In addition to the mitochondria a moderate number of large translucent vacuoles are observed. Some are covered by a single thin membrane but some are lacking in a definite limiting membrane. Some of these vacuoles contain small opaque granular material or an irregular lipid substance but the contents of the majority of these vacuoles seems to be completely electron translucent.

\section{Descending thin limb (Loop of Henle):}

This portion of the nephron consists of two or three cells in the transverse section. The cytoplasm of these cells covers the inner surface of the basement membrane, but perinuclear cytoplasm protrudes into the lumina with their nuclei. The thickness of the cytoplasm is approximately $6-7 \mu$ at the perinuclear portion and about $1 \mu$ at the thinnest part of the cytoplasm. Although there are no endothelial poles like those seen in the glomerular endothelial cell, the lateral cell membranes of the adjacent two cells form a complex serrate pattern (Fig. 6).

In the cytoplasm a few mitochondria (mean width $300 \mathrm{~m}_{\mu}$ ), endoplasmic reticulum, a Golgi area and other small granules are observed. They are rather small and few in comparison with those seen at the proximal convolution. Occasionally small projections or processes of the cell are seen at the Juminal surface of the cell.

Irregular infolding of the cell membrane are seen at the basal portion of the cell (indicated by arrows in Fig. 6, 7). These infolding of the cell membrane are assumed to be the undifferentiated basal intussusception. This undifferentiated basal intussusception is the most important feature of the descending thin limb. In electron micrographs of the medulla of the kidney, there is frequently observed two kinds of a canal system of the same diameter. The one has an undifferentiated basal intussusception and the other does not. The former is the descending thin limb and the latter is the capillary. (Fine structure of the capillary will be discussed later.)

\section{Ascending thick limb (Loop of Henle):}

In the cross section of this portion, the luminal space is rather stellate in shape, and the dimension of the ascending thick limb is approximately the same as that of the comparatively straight medullary portion. Luminal surfacing 
cell membrane of the cell is rather smooth except for occasional small projection of the cytoplasm. There is no brush border. The nuclei of these cells are usually irregular in shape and no spherical nuclei could be seen in this part of the nephron. Well developed basal intussusceptions are observed at the basal portion of the cells and many mitochondria with 200 to $400 \mathrm{~m} \mu$ dimensions are seen coincident with the basal intussusception.

In comparing the basal portion, at the perinuclear and supranuclear portions of the cell, the mitochondria are decreased in number and occasionally there are no mitochondria at the supranuclear portion (Fig. 8).

In some cells the Golgi area is observed at one side of the nuclei. In addition to mitochondria and basal intussusceptions, many small vacuoles, endoplasmic reticulum and others are despersed in the cytoplasm. The structure of the cell boundaries presents the same features as those seen at the proximal convolution. Occasionally terminal bar-like structures are seen at the marginal portion of the cell (Fig. 9).

\section{Distal convolution: (Fig. 10)}

Likewise as seen by light microscope, the luminal spaces are always widely open and the epithelial cells are cuboidal or columnar at the distal convolution. The distinctive features of an epithelial cell is its well developed basal intussusception, moderate number of elongated or rod-shape mitochondria, smooth luminal surface and electron translucent cytoplasm. The cytoplasm contains a somewhat lesser number of basal intussusception and mitochondria than those seen in the proximal convolution. The Golgi area and small vesicular components of the cytoplasm are clearly visible owing to the low density of the cytoplasm.

\section{Collecting tubule:}

In a longitudinal sectioning of this portion, the cells are semicircular in shape and approximately $8-10 \mu$ in height at the middle portion of the cell. At the free surface of the cell, there are small irregular projection of the cytoplasm (Fig. 12).

At the basal portion of the cell there are undifferentiated basal intussusceptions, but no relation to the mitochondria can be seen. In the cytoplasm except for the Golgi area and the undifferentiated basal intussusceptions, there are a few mitochondria, the dimensions of which are from 200 to $300 \mathrm{~m}_{\mu}$. In addition to these organella, a few small vacuoles are observed at the supranuclear lesion. The boundary of the two cells is zig-zag and has a translucent intercellular space. 
In the longitudinal section, so-called dark cells are mingled with the cells of the normal tubule cell (Fig. 14). The number of mitochondria and RNA granules are extremely abundant in these dark cells. The ratio of the clear cell to the dark cell vary according to the portion from which the specimens are taken. The number of mitochondria of the dark cells is several to ten times more than that seen in clear cells.

Papillary duct:

Transverse sectioning of this portion shows more than ten cells arranged in a layer forming a circular or ovoid tubular structure (Fig. 13). The cells are cylindrical or trapezoid in shape and the boundary line of the two cells are rather serrated. There are no brush borders. In the cytoplasm of the cell, a few endoplasmic reticulum, mitochondria and many small vesicles are observed. Mitochondria are small and few in number. No definite basal intussusception can be seen. Generally, the papillary duct cells are more or less electron translucent owing to meagerness of content (Fig. 15).

Capillary (Fig. 11, 16)

Two kinds of capillary are observed in the medulla of the kidney. The first is approximately the same in dimension as that of the descending thin limb of Henle's loop. Usually, a transverse sectioning of these capillaries indicates this as being rather circular in lower magnified photographs, and quite similar in feature to that of the descending thin limb.

Thin endothelial sheets of these capillaries cover the inner surface of the basement membrane. These endothelial sheets are lacking in undifferentiated basal intussusception which is always seen at the basal portion of the descending thin limb.

Another difference is that the endothelial cytoplasm is divided into more numerous parts than those of the thin limb. This fact would indicate that the endothelial sheet of the capillary is higher divided and its cytoplasmic projections seem to be longer. Furthermore the basement membrane of this portion is occasionally divided into two membranes which contain cytoplasmic projections of adventitial cells or adventitial cell itself. This finding is identical to that of the capillary of the heart which is described by Kisch(3).

The second type of capillary is rather irregular in shape and has a much thinner endothelial sheet than that of the first type. And there are small interruptions of the endothelial sheet. The second type of capillary is the same as is usually seen in the stroma of the renal cortical tissue. No cytoplasmic structures within or around the basement membrane are seen. 


\section{COMMENTS}

Though classification of the nephron by part has been performed by many investigators, the most practical one is that of Maximow and Bloom. However we found it necessary to add the comparatively straight medullary portion to Maximow-Bloom's classification after our electron microscopic observation of the tubule cells. Hence the classification of the nephron by part stated in this article is as described herein: viz, glomerulus, proximal convolution, comparatively straight medullary portion, the descending thin limb of loop of Henle, the ascending thick limb of loop of Henle, distal convolution, collecting tubule and papillary duct.

Comparatively straight medullary portion:-The reason why comparatively straight medullary portion must be added to Maximow-Bloom's classification is because of the existence of definite structural differences between the cells of proximal convolution and the comparatively straight medullary portion. There are similarities in structure between the two, such as a well differentiated basal intussusception, large and abundant mitochondria and brush border. But the brush border of the former is more tightly packed and closely arranged than that of the latter. Furthermore, the latter is extremely abundant in RNA granules and more electron dense than the former. Also the dimensions of the cells of the proximal convolution are much larger than those of the comparatively straight medullary portion. These apparent differences of the two portion suggest a functional difference of these portions in their physiological condition. So, in order to describe the minimal and miscellaneous pathological changes of these cells, it is believed more logical to differentiate the proximal convolution into two parts, viz. proximal convolution and the comparatively straight medullary portion.

Basal intussusception:- Since Pease reported on the existence of the basal intussusception and its fine structure, several works regarding this structure as seen in the proximal convolution have been reported. As regards the basal intussusception of the proximal and distal convolution, we have no new details to add to reports by various other workers.

However in this study, basal intussusception are observed not only in proximal and distal convolution but also in the thin and thick limb of Henle's loop and collecting tubule. In the descending thin limb of Henle's loop and collecting tubule, this structure is seen in an undifferentiated form. The existence of the undifferentiated form is the most important point between the differentiation of the thin limb of Henle's loop and the capillary. In the papillary duct there are no basal intussusceptions. 
As briefly mentioned before, sometimes it is very difficult to discern the difference between the thin limb of Henle's loop and the capillary in the medulla of the kidney. One means of differentiation is to ascertain whether they have undifferentiated basal intussusception or not, as mentioned above. The other is the segmentation of the cytoplasm. Usually, the thin limb of Henle's loop is covered with three or four epithelial cells, on the other hand the capillary are covered by many small segments of cytoplasm. Furthermore, in the basement membrane of the latter, there are adventitial cells or their projections. This fact would suggest that differentiation of the two canal systems is somewhat difficult in light microscopy especially in its pathological condition.

Relationship of the basal intussusception and mitochondria:--In tubular epithelium, usually there is an intimate relationship between the basal intussusception and mitochondria. At the proximal convolution, thick limb of Henle's loop and distal convolution, a well developed basal intussusception and simultaneously abundant mitochondria exist in the cytoplasm. On the other hand, in other parts of the nephron, such as the thin limb of Henle's loop and collecting tubule, the basal intussusceptions are poorly differentiated; also the mitochondria are small in size and few in number and are scattered irregularly in the cytoplasm. The co-existence of the basal intussusception and mitochondria highly suggests that these structure play an important role in tubular function. The correlation between fine structures of cellular organella in tubule cells by parts and their functions will be clarified after various systematic and experimental research on the kidney.

Capillary:-An electron micrograph, indicates two kinds of capillary in the medulla of the kidney. The one is as described herein, circular and possessing adventitial cells in their basement membrane. The others are irregular or triangular in shape when transversely sectioned, their endothelial cells are much thinner than the former, and small interruptions of the cytoplasm are observed in their cytoplasm. Also there are no adventitial cells within or around their basement membrane. Based on anatomical common sense, it is very easy to assume that the former is a proximal and the latter a distal capillary of the circulatory system, however we have no demonstrative certainty to determine this point. Further study is required on this point.

\section{SUMMARY}

An electron microscopic study of the renal tubule cells of rabbit by part was performed.

1. Because of the apparent structural differences between the cells of 
proximal convolution and the comparatively straight medullary portion, we added the straight medullary portion to Maximow-Bloom's classification of the nephron.

2. In all parts of the nephron except the papillary duct, basal intussusceptions were observed either in a well differentiated or an undifferentiated form.

3. Two types of capillaries were seen in the medulla of the kidney.

After the authois had corrected their first proof, the authors were given a chance to read Rhodin's work (International Review of Cytology, VII: 485-534, 1958). The authors believe that Rhodin's work is very cxcellent.

The authors wish to express their gratitude to Prof. Tadayoshi Kobayashi and Dr. Yonosuke Watanabe for suggesting this investigation as well as for constant guidance in the course of work.

\section{LITERATURE}

1. Bargmann, W., Knoop, A., und Schiebler, Th. H.: Zeitschrft. f. Zellforsch., 42: $386,1955$.

2. Cowdry, E. V.: A textbook of Histology. Lead and Febiger, Philadelphia, 1950.

3. Kisch, B.: Deutsch. Med. Wschrft., 82: 605, 1957.

4. Maximow, A. A. and Bloom, W.: A textbook of histology, Ed. 5. Saunders, Philadelphia and London, 1957.

5. Möllendorff, v. W.: In: Handb. d. mikr. Anat. d. Mensch. VII/1, Julius Springer, Berlin, 1930.

6. Pease, D. C.: Anat. Rec. 121: 723, 1955.

7. Pease, D. C.: J. Histochem. and Cytochemistry., 3: 259, 1955.

8. Rhodin, J.: Correlation of ultrastructural organization and function in normal and experimentally changed proximal convoluted tubule cells of the mouse kidney. Karolinska Institute, Stockholm, 1954.

9. Rhodin, J.: Am. J. of Med., 24: 661, 1958.

10. Ruska, H., Moore, D. H. and Weinstock, J.: J. Biophys. \& Biochem. Cytol., 3: $249,1957$.

11. Sakaguchi, H.: Keio J. of Med. 4: 103, 1955.

12. Sakaguchi, H., Suzuki, Y. and Yamaguchi, T.: Acta path. Jap., 7: 53, 1957.

13. Sjöstrand, F. S. and Rhodin, J.: Exper. Cell res., 4: 426, 1953.

14. Takaki, F., Yasuda, H., Aoyagi, S., Shimizu, Y. and Hagiwara, A.: Acta path. Jap. 6: 99, 1956. 


\section{EXPLANATION OF PLATES}

Fig. 1. The basal portion of a proximal convolution; basal intussusception (BI) and mitochondria $(M)$ can be seen. $\times 24,000$

Fig. 2. The longitudinally sectioned brush border. $\times 32,000$

Fig. 3. The lower magnified proximal convolution; the dome cells (DE) can be seen. $\times 2,400$

Fig. 4. A nephron as seen on right side of this photograph is a comparatively straight medullary portion and on left side is a thick limb of Henle's loop. $\times 10,000$

Fig. 5. The higher magnified comparatively straight medullary portion. The luminal space is definitely open. $\times 18,000$

Fig. 6, 7. Show the descending thin limbs of Henle's loop. Irregular infolding of the cell membrane (undifferentiated basal intussusception) are noted. (arrows indicate) Fig. 6: $\times 7,000$ Fig. 7: $\times 8,000$

Fig. 8. A ascending thick limb of Henle's loop in lower magnification. $\times 8.000$

Fig. 9. The higher magnified ascending thick limb. Facing the luminal surface a terminal bar like structure is seen. (arrows indicate) $\times 15,000$

Fig. 10. A distal convolution. At the apical portion no brush borders are seen. G. is the Golgi area. $\times 7,000$

Fig. 11. A. is a capillary having the advential cell projection (ad) within its basement membrane and $B$. is a capillary having the thinner endothelial cells and endothelial poles. (arrows indicate) $\times 9,000$

Fig. 12. Indiactes a colecting tubule in a longitudinal sectioning. The small projections facing the luminal surface and undifferentiated basal intussusception are seen. $\times 8,000$

Fig. 13. A papillary duct in the transverse sectioning. $\times 2,100$

Fig. 14. A collecting tubule in the longitudinal sectioning. So-called dark cells (DC) are seen on this photograph. $\times 7,500$

Fig. 15. A papillary duct. The cells are more or less elctron translucent. $\times 13,000$

Fig. 16. Shows higher magnification of the capillary wall. A. is a capillary having the cytoplasmic projection of the adventitial cell (ad) within its basement membrane, and there are no undifferentiated basal intussusception, the right one is a capillary having the thinner endothelial cell and endothelial pole (arrows indicate). $\times 14,000$

Fig. 17, 18. Diagrams of renal tubule cells. 


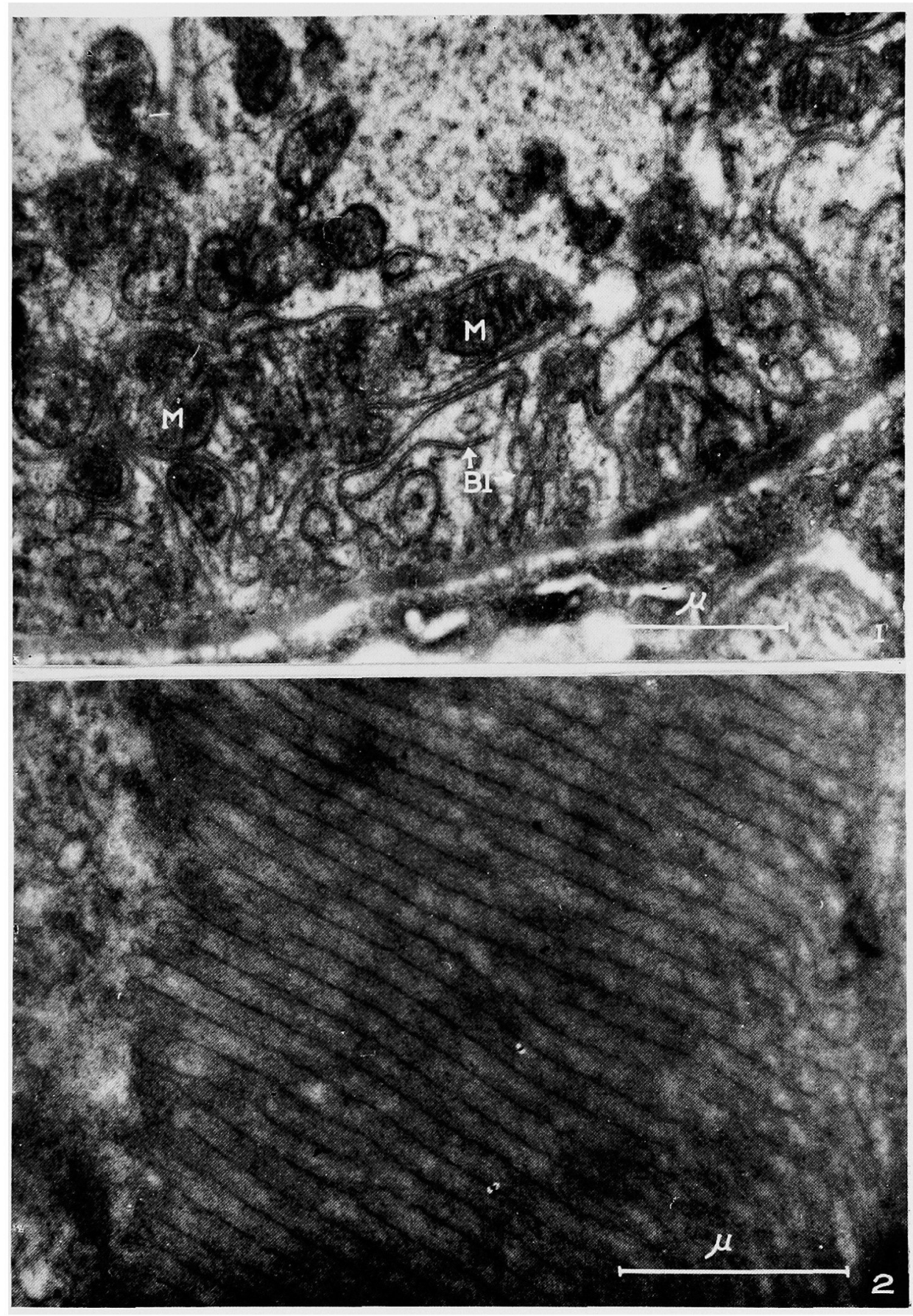




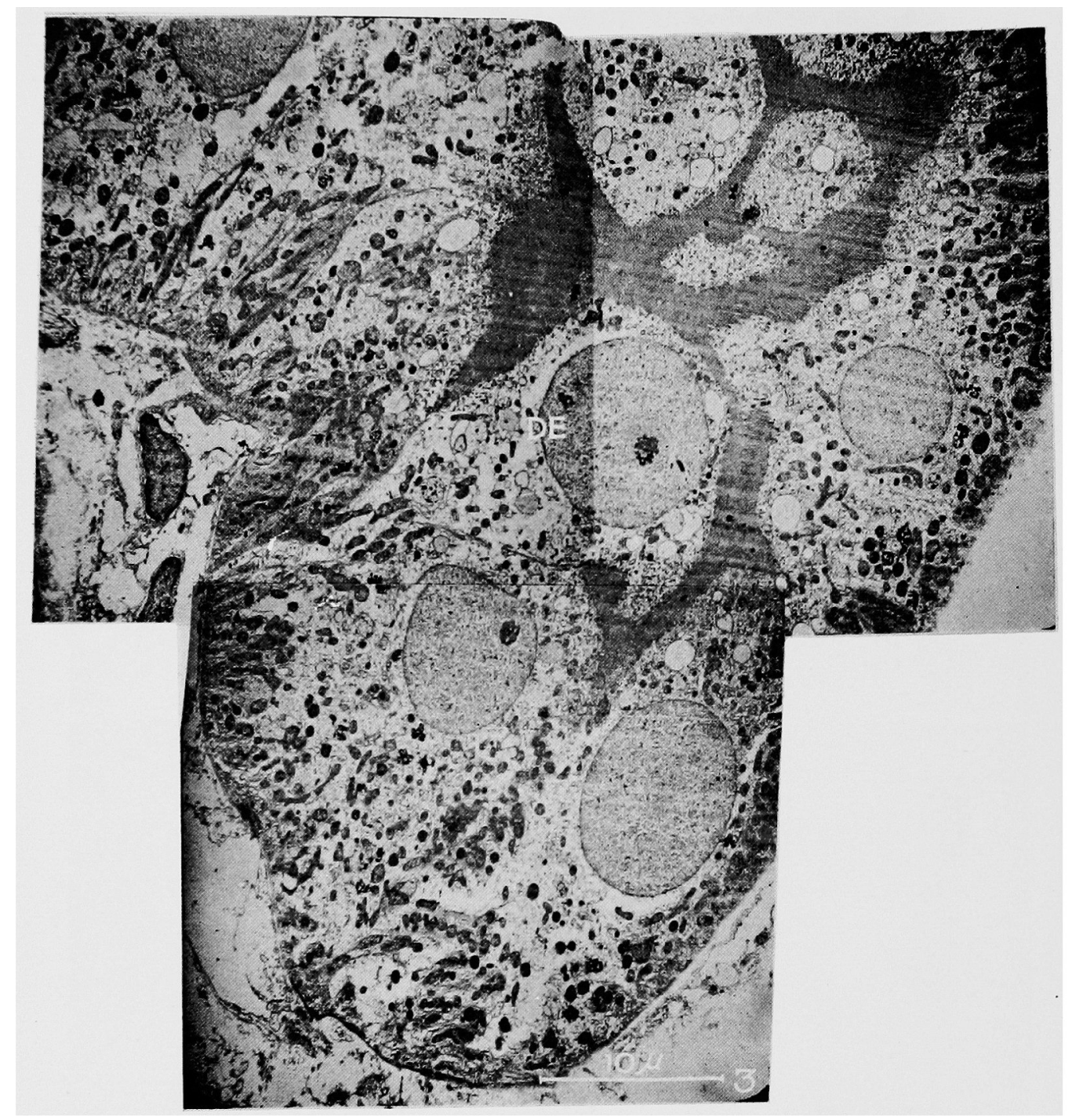

HIROSHI SAKAGUCHI 

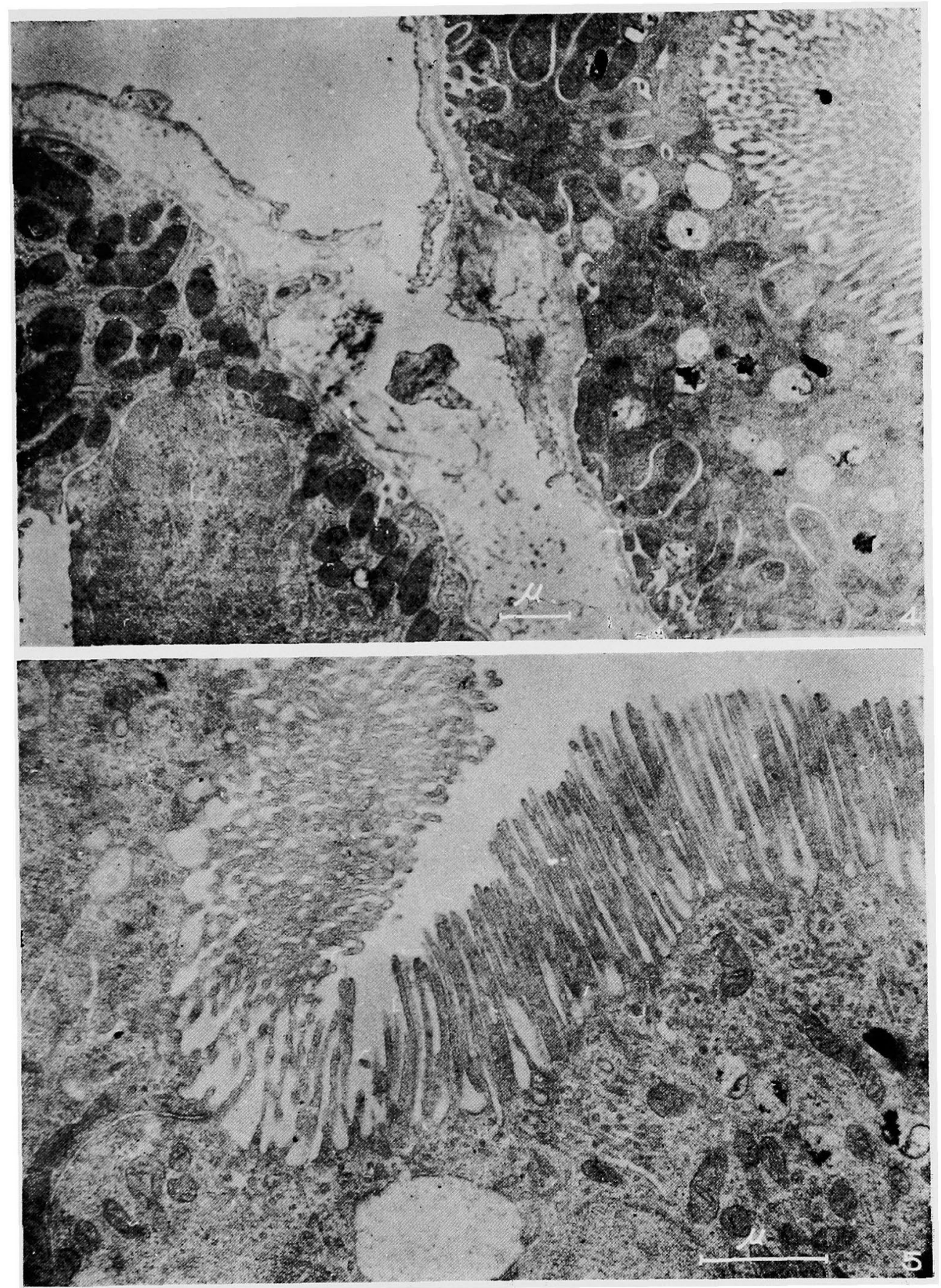

HIROSHI SAKAGUCHI 


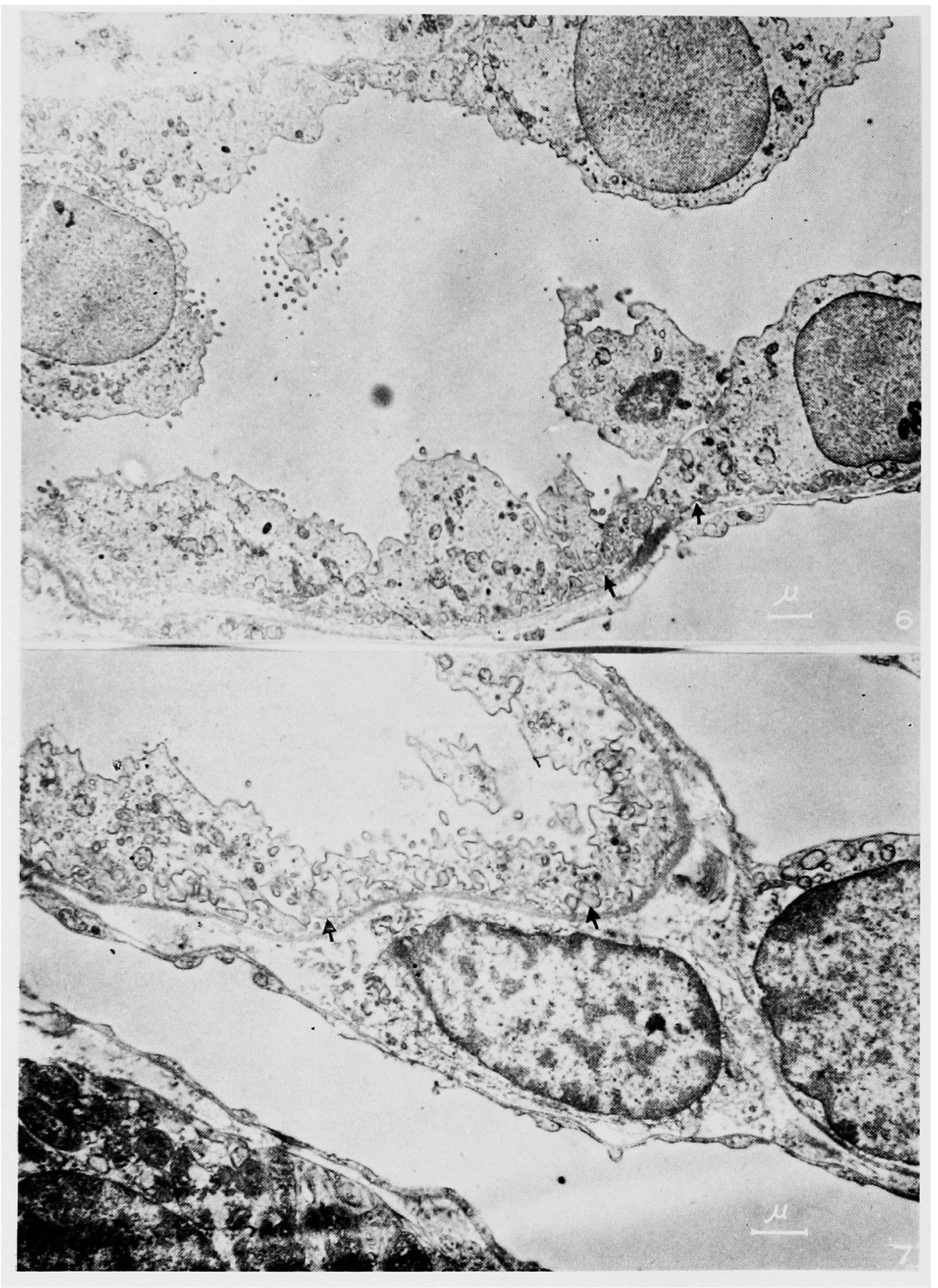

HIROSHI SAKAGUCHI 

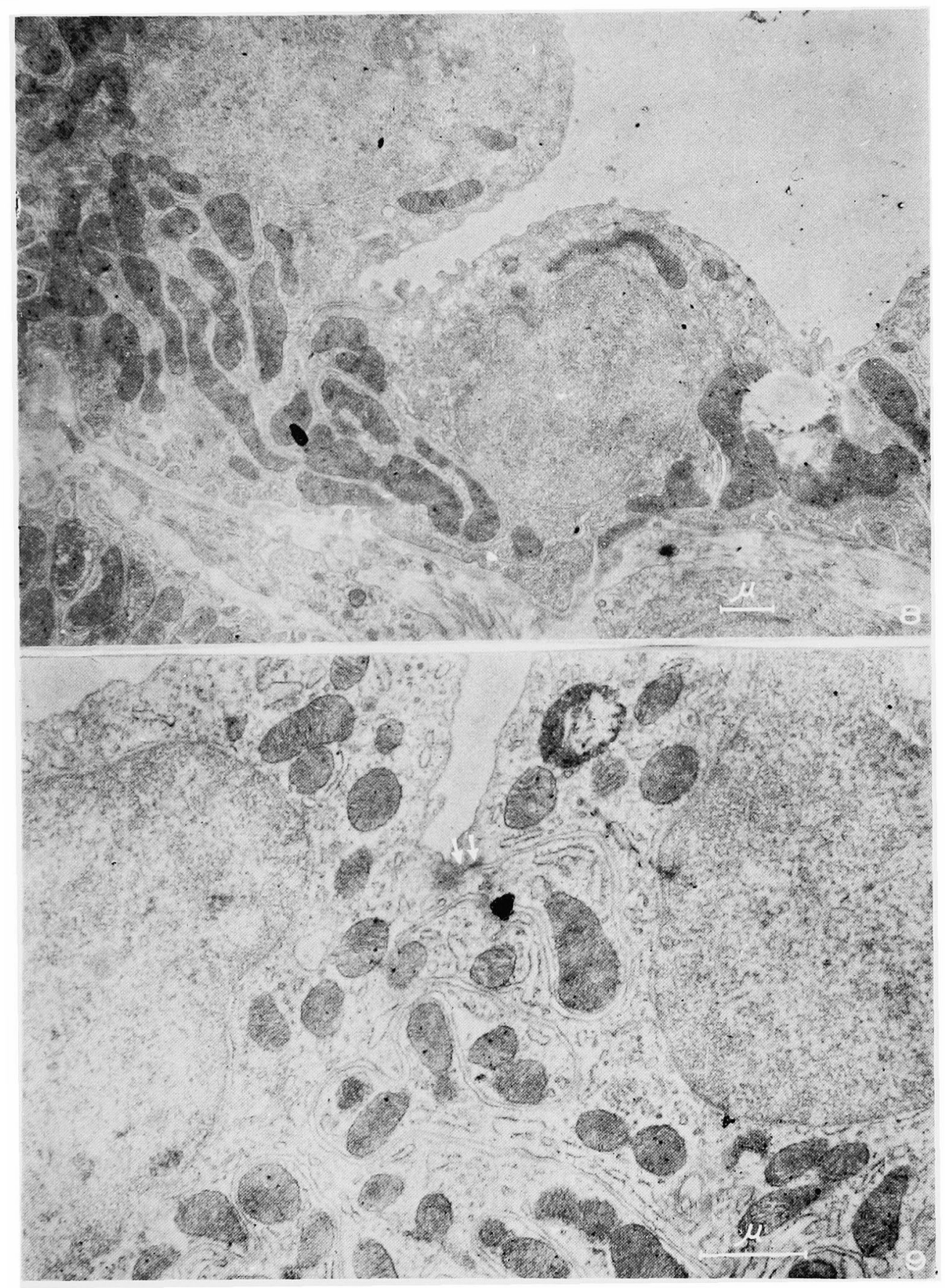

HIROSHI SAKAGUCHI 


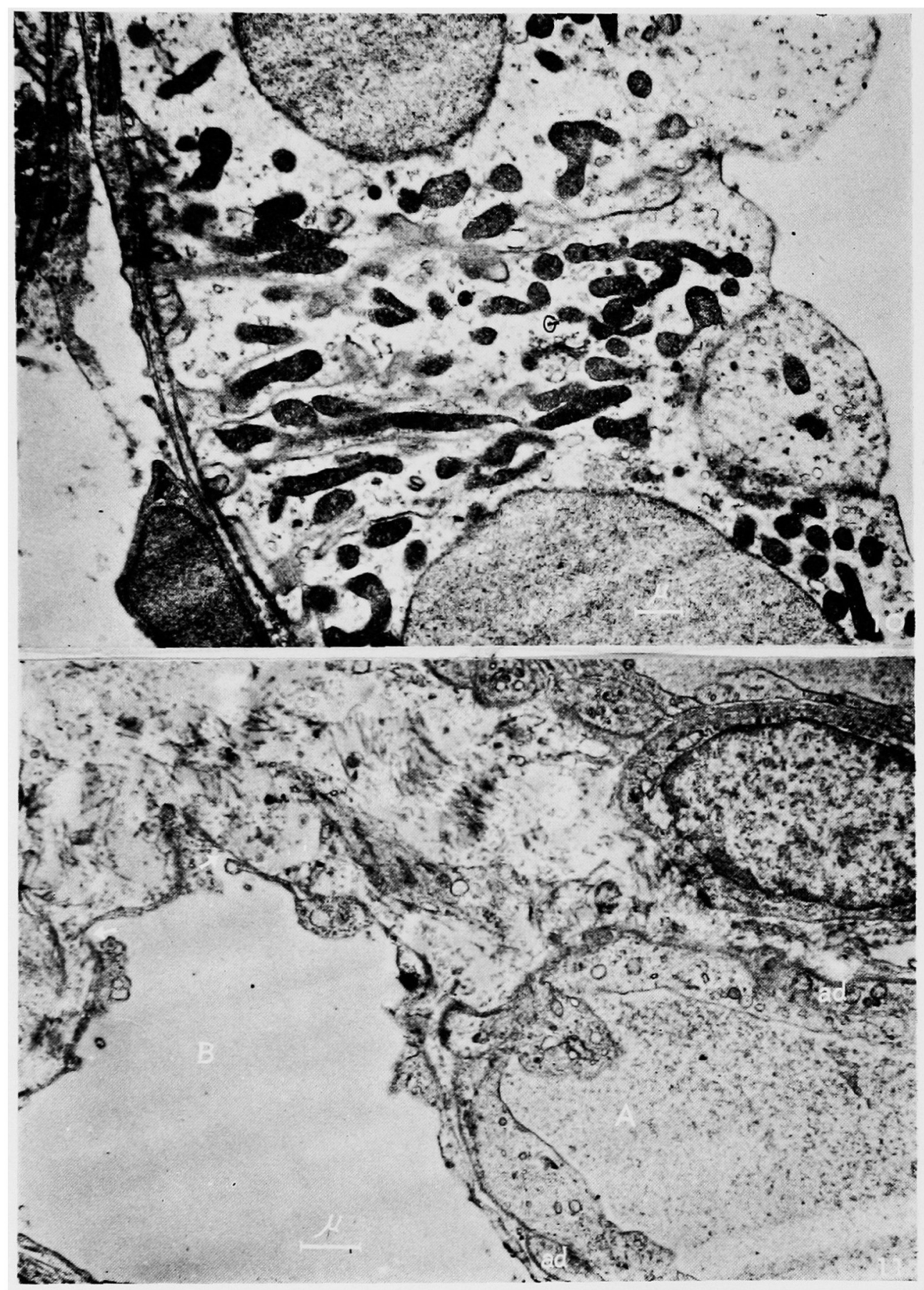

HIROSHI SAKAGUCHI 


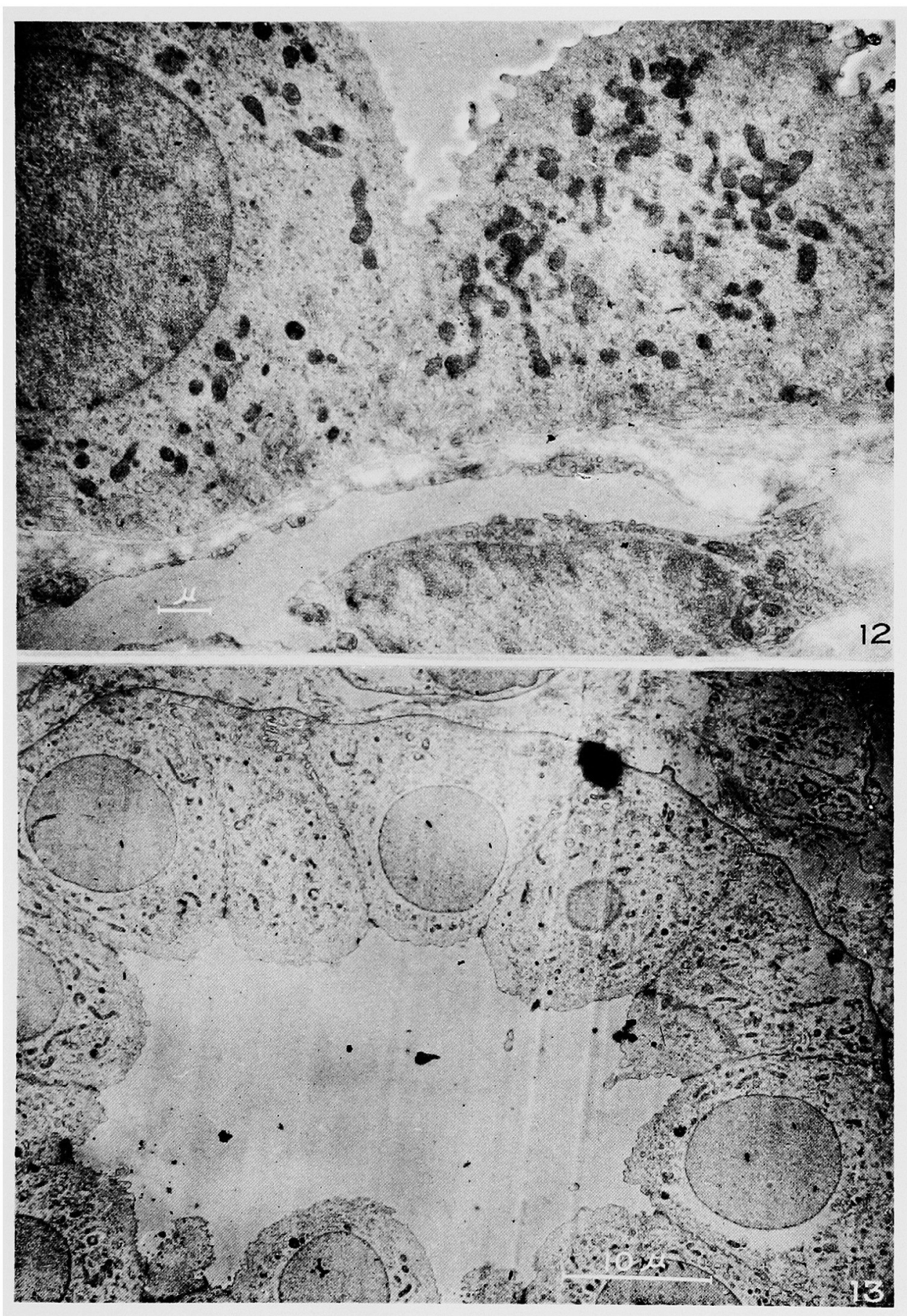

HIROSHI SAKAGUCHI 


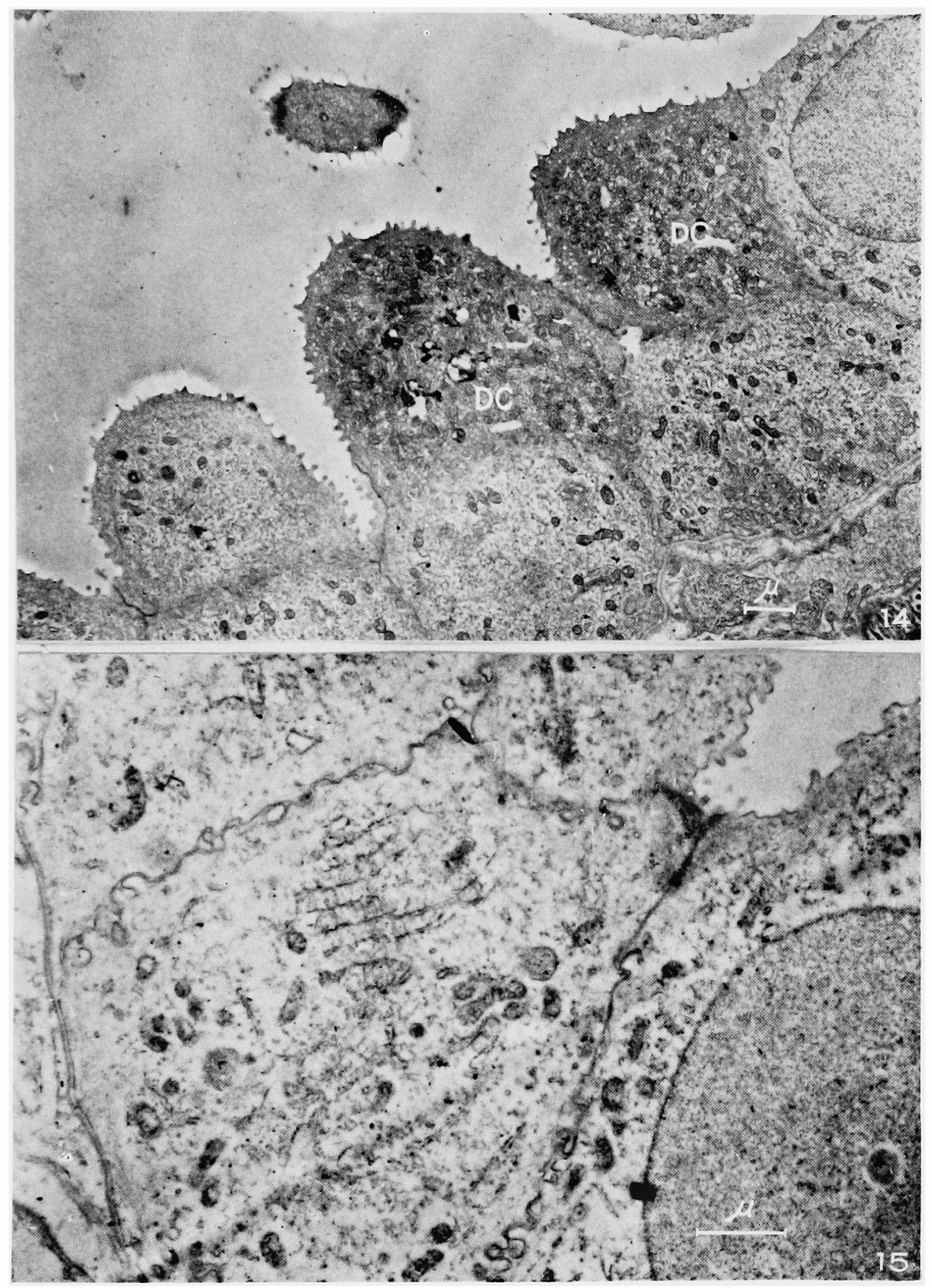

HIROSHI SAKAGUCIH 


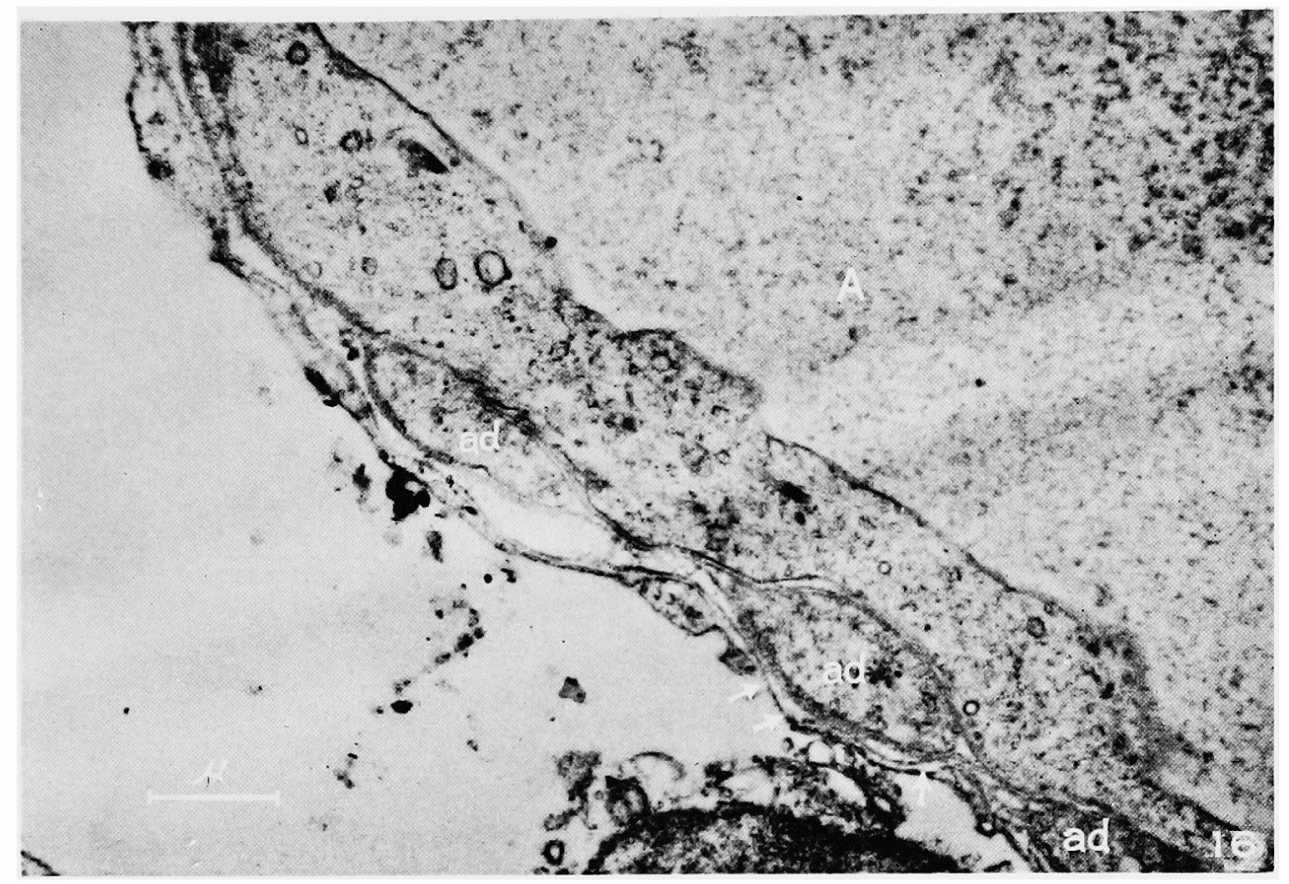

HIROSHI SAKAGUCHI 
Diagram of renal tubule cells

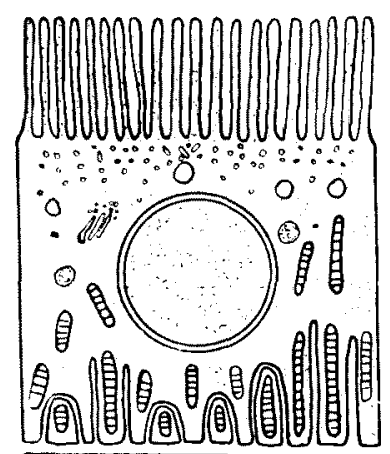

Proximal convolution

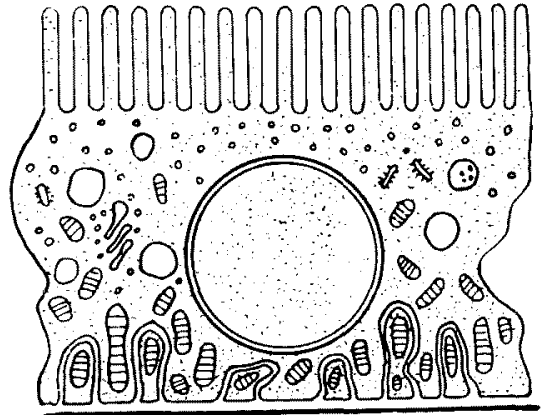

Comporatively straight medullary portion

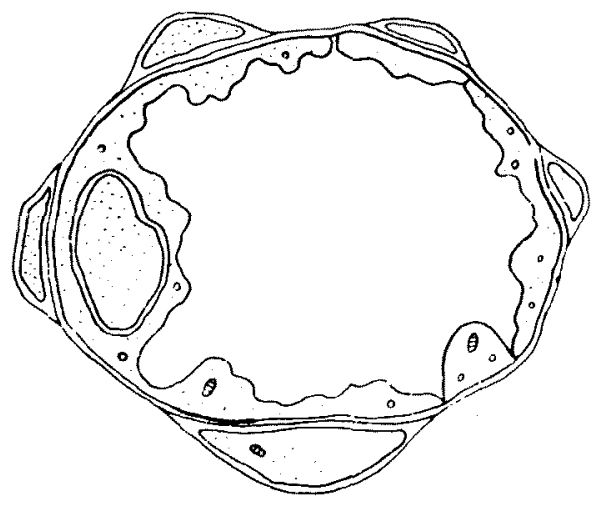

Copillory (A)

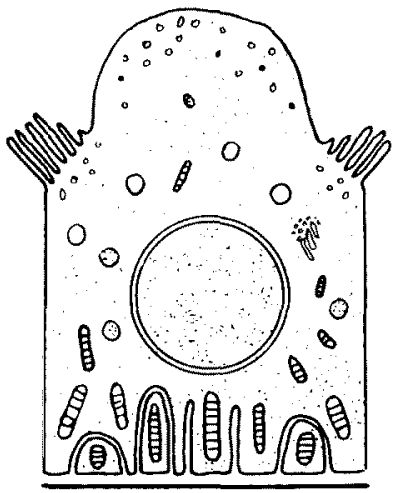

Dome cell

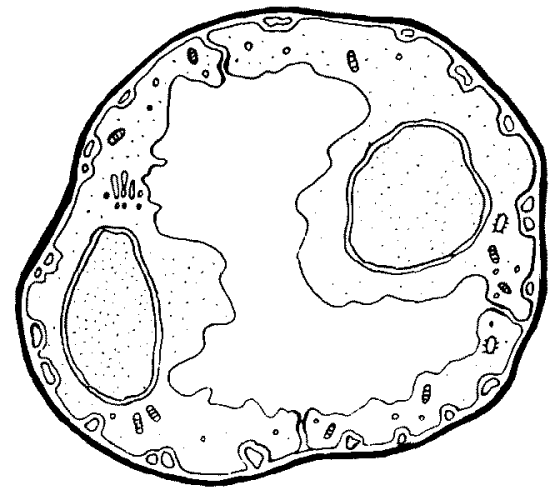

Thin limb of loop of Henle

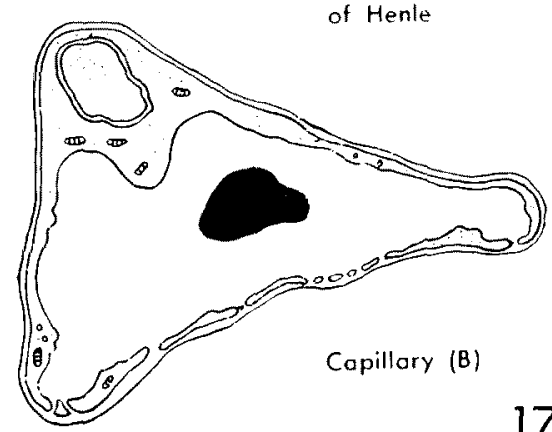




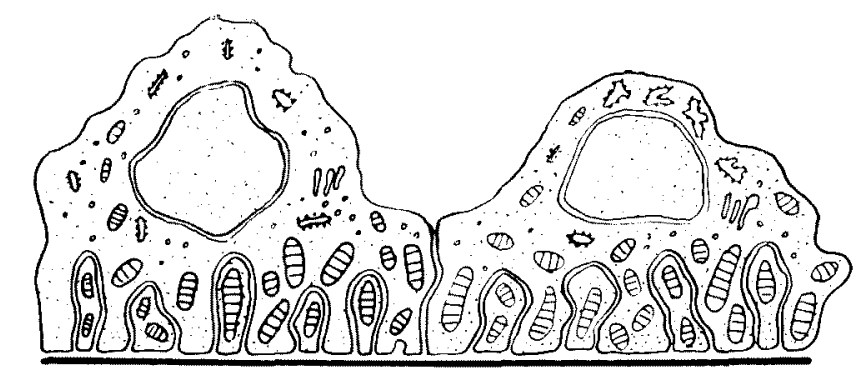

Thick limb of loop of Henle

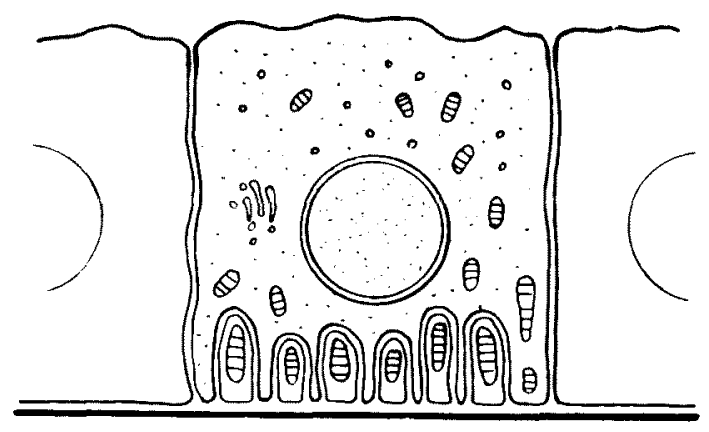

Distal convolution

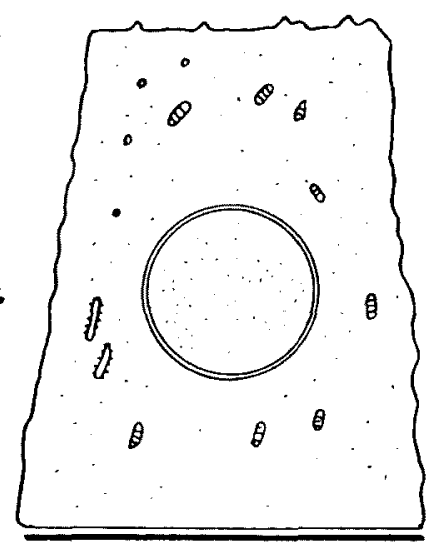

papillary duct

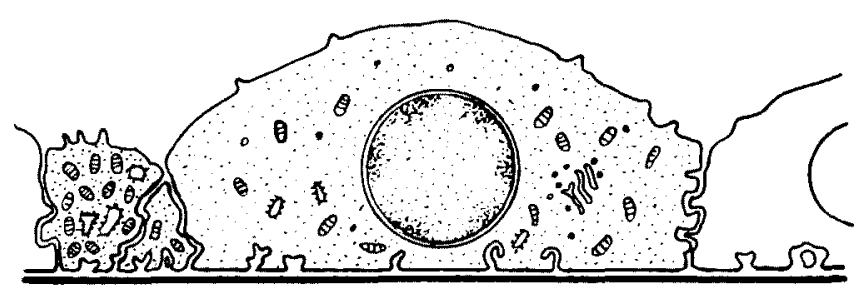

Collecting tubule 